\title{
Association between Platelet/Lymphocyte Ratio and Angiographic No-Reflow in Patients with None-St Segment Elevation Acute Myo- cardial Infarction Undergoing Primary Coronary Intervention
}

\author{
Ramazan Asoğlu (iD ${ }^{1^{*}}$, Abdülmecit Afşin ${ }^{2}$, Emin Asoğlư ${ }^{3}$ and Arif Süner ${ }^{1}$ \\ ${ }^{1}$ Department of Cardiology, Adıyaman University Training and Research Hospital, Turkey \\ ${ }^{2}$ Department of Cardiology, Kahta Community Hospital, Turkey \\ ${ }^{3}$ Department of Cardiology, Mardin Community Hospital, Turkey
}

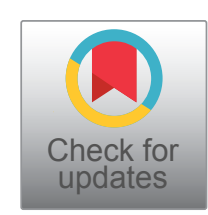

*Corresponding author: Ramazan Asoğlu, Department of Cardiology, Training and Research Hospital, Adıyaman University, Adıyaman, Turkey, Tel: +90-530-776-37-12, Fax: +90-416-223-38-42

\begin{abstract}
Introduction: Inflammation and platelet activation play a central role in the initiation and progression of the atherosclerosis process. The Platelet-to-lymphocyte ratio (PLR) is a new prognostic marker in coronary artery disease. The PLR is a significant independent predictor of longterm mortality after none-ST elevated myocardial infarction (NSTEMI). We aimed to evaluate the relationship between PLR and no-reflow (NR) in patients with NSTEMI.
\end{abstract}

Material and methods: The present study included 173 patients with NSTEMI. The patients were classified into two groups as follows: 115 patients in the NR group and 58 patients in the normal reflow group. NR was defined as coronary thrombolysis in myocardial infarction (TIMI) flow grade $\leq 2$ after vessel recanalization with primary percutaneous coronary intervention. The PLR was calculated from the complete blood count.

Results: The PLR values of the patients with NR were significantly higher than those of patients with normal reflow (108.6 (14.6-511.3) vs. 91.7 (17.2-225.3), $p=0.01)$. Also, neutrophil-to-lymphocyte ratio (NLR) was significantly higher in the NR group than the normal-reflow group (3.0 (0.3$16.5)$ vs. $2.3(0.01-12.5), p=0.02)$. The Correlation between the PLR and NLR was positive and significant $(r=0.68, p$ $<0.001)$.

Conclusion: This study showed that PLR is an independent predictor of NR in patients with NSTEMI.

\section{Keywords}

Platelet-to-lymphocyte ratio, Angiographic no-reflow, NonST segment elevation myocardial infarction, Percutaneous coronary intervention

\section{Introduction}

Acute coronary syndrome (ACS) is a leading cause of death worldwide, and patients with none-ST elevation myocardial infarction (NSTEMI) have a higher long-term mortality risk due to the prevalence of comorbidities and multi-vessel coronary artery disease (CAD) [1]. The diagnosis and prediction of significant CAD in NSTEMI can be challenging, and cardiac biomarkers, electrocardiography, symptoms, and cardiac risk factors are used to diagnose NSTEMI [2]. Inflammation and platelet activation plays a central role in the initiation and progression of the atherosclerosis process [3]. Also, increased platelet activation is associated with major adverse cardiovascular consequences [4]. On the other hand, lymphocyte count is inversely correlated with inflammation, and a low blood lymphocyte count is related to worse cardiovascular outcomes in patients with coronary artery disease [5]. The Platelet to lymphocyte ratio (PLR) was introduced as a potential marker for excess thrombotic activity [6] and inflammation in cardiac disorders [7]. The PLR has recently emerged as a significant predictor of major adverse consequences in cardiovascular disease [8]. Also, the PLR is a significant independent predictor of long-term mortality after NSTEMI [7]. However, there were no data regarding its predictive role for angiographic no-reflow (NR) in NSTEMI. Therefore, this study aimed to evaluate

Citation: Asoğlu R, Afşin A, Asoğlu E, Süner A (2019) Association between Platelet/Lymphocyte Ratio and Angiographic No-Reflow in Patients with None-St Segment Elevation Acute Myocardial Infarction Undergoing Primary Coronary Intervention. Int J Clin Cardiol 6:159. doi.org/10.23937/23782951/1410159

Accepted: September 24, 2019; Published: September 26, 2019

Copyright: (c) 2019 Asoğlu R, et al. This is an open-access article distributed under the terms of the Creative Commons Attribution License, which permits unrestricted use, distribution, and reproduction in any medium, provided the original author and source are credited. 
the relationship between PLR and angiographic NR in patients with NSTEMI.

\section{Material and Method}

From January 2017 to January 2018, a totally of 173 consecutive patients with NSTEMI, which underwent primary percutaneous coronary intervention (pPCl) within 24 hours of admission in Adıyaman University Training and Research Hospital, were enrolled into the study. CAD was defined as the presence of stenosis of at least $50 \%$ of the vessel diameter in any of the main coronary arteries, according to the American College of Cardiology/American Heart Association (ACC/AHA) lesion classification [9]. Significant CAD was defined as $\geq$ $70 \%$ stenosis in at least one major coronary artery or major side branch.

All of the patients were orally pretreated with 300 $\mathrm{mg}$ aspirin and $600 \mathrm{mg}$ clopidogrel at the time of diagnosis before the intervention. Heparin $(100 \mathrm{lU} / \mathrm{kg})$ was administered before transportation to the catheterization laboratory or when the coronary anatomy was first defined. Baseline coronary angiography was performed using standard techniques (Siemens Axiom Artis zee 2011; Siemens Healthcare, Erlangen, Germany). Each coronary artery was displayed in at least two different plane images. lopromide, as a contrast agent (Ultravist-370, Bayer Schering Pharma, Germany), was used in all subjects. All of the $\mathrm{pPCl}$ procedures were performed with a standard femoral approach with a 6-French guiding catheter (Launcher; Medtronic, Minneapolis, Minnesota, USA). An angiographic evaluation was made by visual assessment. After administration of unfractionated heparin conventional wire crossing, direct stenting was implanted whenever possible, and if necessary, balloon predilatation was carried out. For each procedure, interventional success was defined as reducing obstruction and stenosis to $30 \%$ of the infarct-related artery just after primary angioplasty.

The Thrombolysis in Myocardial Infarction (TIMI) flow grade was evaluated by an experienced interventional cardiologist, blinded to the patients clinical data, using quantitative cardiovascular angiographic software (Axiom Sensis XP; Siemens, Munich, Germany). The patients were divided into two groups based on the postintervention TIMI flow grade: normal-reflow group and NR group. Normal-reflow was defined as post-intervention TIMI grade 3 flow. NR is defined as an inability to restore blood flow to previously ischemic myocardium even after the return of infarct-related epicardial coronary artery patency due to microvascular obstruction. NR group consisted of both patients with angiographic no-reflow [10] (defined as post-intervention TIMI grade 0-1-2 flow). The syntax score (SX score) for each patient was calculated by scoring all coronary lesions with diameter stenosis of at least $50 \%$, in vessels at least $1.5 \mathrm{~mm}$, using the SX score algorithm, and is available on the SX score website (Available at http:// www.syntaxscore.com).

Blood samples are collected from the antecubital vein by an atraumatic puncture and are sent to the laboratory for analysis within 1 hour after collection. In all patients, blood samples were drawn on admission. Common blood counting parameters stored in citrate-based anti-coagulated tubes were measured by Coulter LH 780 Hematology Analyzer (Beckman Coulter Ireland Inc, Mervue, Galway, Ireland) within 5 minutes of sampling. Glucose, creatinine, lipid profile, and cardiac enzymes were determined by standard methods. PLR was calculated as the ratio of platelet count to lymphocyte count. The neutrophil to lymphocyte ratio (NLR) was calculated as the ratio of neutrophil count to lymphocyte count. The inclusion criteria of the study were as follows: Documented gradual rise and fall of serum troponin levels with a peak value of $>0.5 \mathrm{ng} / \mathrm{ml}$. An NSTEMI diagnosis was based on elevated cardiac enzymes with typical chest pain and electrocardiographic changes, the notable absence of ST-segment elevation, suggestive of myocardial ischemia [11]. Typical chest pain was evaluated as follows: More than 20 minutes ( $\mathrm{min}$ ) in duration, new-onset angina, and an increase in its frequency and duration or severity. A cardiologist confirmed the NSTEMI diagnosis. Exclusion criteria included cardiogenic shock on admission, serious arrhythmias with hemodynamic instability, history of coronary artery bypass greeting, active infections, systemic inflammatory disease history, known malignancy, hematologic disorders, liver disease, and renal failure.

From medical records, we obtained demographic information, cardiovascular history, and risk factors for CAD, and treatment received during the in-hospital period. Laboratory studies, including Platelet and lymphocyte counts, were analyzed. Clinical information included data on systemic hypertension (HTN), diabetes mellitus, dyslipidemia, smoking, and previous history of CAD. Diabetes was based on a fasting blood sugar level $\geq 126$ $\mathrm{mg} / \mathrm{dL}$ or use of an anti-diabetes medication. Hypertension was reported for systolic blood pressure $\geq 140$ $\mathrm{mmHg}$, diastolic blood pressure $\geq 90 \mathrm{mmHg}$ or use of antihypertensive agents. Hyperlipidemia was reported for total cholesterol $\geq 200 \mathrm{mg} / \mathrm{dL}$, low-density lipoprotein (LDL) level $\geq 130 \mathrm{mg} / \mathrm{dL}$ or use of cholesterol-lowering medication. Smoking included active or previous ( $>10$ pack-years) tobacco use. 12-lead electrocardiography (ECG) was recorded in each patient just after hospital admission. At $24 \mathrm{~h}$ to $72 \mathrm{~h}$ after revascularization, transthoracic echocardiography study was performed with a 3.5-MHz transducer to all patients (Vivid 3; GE Medical System, Horten, Norway). Simpson's method was used to assess left ventricular ejection fraction (LVEF), as recommended by the American Society of Echocardiography [12]. 
Table 1: Baseline clinical characteristics of the study population.

\begin{tabular}{|c|c|c|c|}
\hline & No Reflow & Normal Reflow & $\mathbf{P}$ \\
\hline Age (years) & $63.13 \pm 10.77$ & $63.51 \pm 10.43$ & 0.23 \\
\hline Male\% (n) & $57(66)$ & $65(38)$ & 0.08 \\
\hline Hypertension\% (n) & $34(40)$ & $36(22)$ & 0.28 \\
\hline Hyperlipidemia\% (n) & $21(25)$ & $27(16)$ & 0.62 \\
\hline Diabetes mellitus\% (n) & $26(30)$ & $31(18)$ & 0.49 \\
\hline Family history of CAD\% (n) & $45(52)$ & $43(25)$ & 0.36 \\
\hline Smoking\% (n) & $43(50)$ & $48(28)$ & 0.30 \\
\hline Ejection Fraction (\%) & $55(20-65)$ & $55(25-65)$ & 0.82 \\
\hline Systolic BP (mmHg) & $120(90-160)$ & $120(90-170)$ & 0.41 \\
\hline Diastolic BP (mmHg) & $80(55-100)$ & $80(60-100)$ & 0.35 \\
\hline Heart rate (bpm) & $75(40-120)$ & $(50-130)$ & 0.87 \\
\hline ASA $\%(n)$ & $27(31)$ & $31(18)$ & 0.52 \\
\hline Beta blocker\% (n) & $27(31)$ & $31(18)$ & 0.35 \\
\hline Clopidogrel\% (n) & $5(6)$ & $13(8)$ & 0.44 \\
\hline ACE inhibitor/ARB\% (n) & $35(41)$ & $46(27)$ & 0.16 \\
\hline CCB\% (n) & $7(8)$ & $10(6)$ & 0.44 \\
\hline Diuretic\% (n) & $32(37)$ & $17(10)$ & 0.05 \\
\hline Statin\% (n) & $24(28)$ & $34(20)$ & 0.74 \\
\hline OAD\% (n) & $22(26)$ & $34(20)$ & 0.73 \\
\hline HISTORY PCI\% (n) & $18(21)$ & $24(14)$ & 0.61 \\
\hline HISTORY MI\% (n) & $13(16)$ & $17(10)$ & 0.56 \\
\hline
\end{tabular}

CAD: Coronary Artery Disease; ACE/ARB: Angiotensin-Converting-Enzyme/Angiotensin-Receptor-Blocker; CCB: CalciumChannel-Blocker; OAD: Oral-Anti-Diabetic; PCl: Percutaneous-Coronary-Intervention; MI: Myocardial-Infarction.

Table 2: Angiographic and laboratory measurements of study groups.

\begin{tabular}{|l|l|l|l|}
\hline & No Reflow & Normal Reflow & p \\
\hline $\mathrm{Na}(\mathrm{mmol} / \mathrm{L})$ & $137.99 \pm 2.55$ & $137.26 \pm 2.58$ & 0.06 \\
\hline $\mathrm{K}(\mathrm{mmol} / \mathrm{L})$ & $4.10 \pm 0.43$ & $4.29 \pm 0.50$ & 0.09 \\
\hline Creatinine $(\mathrm{mg} / \mathrm{dl})$ & $0.9(0.6-1.8)$ & $0.9(0.5-1.8)$ & 0.49 \\
\hline Serum glucose $(\mathrm{mg} / \mathrm{dl})$ & $125(78-300)$ & $123(80-367)$ & 0.79 \\
\hline Troponin-T $(\mathrm{ng} / \mathrm{ml})$ & $0.2(0.01-10.20)$ & $0.1(0.01-9.6)$ & $\mathbf{0 . 0 4}$ \\
\hline Creatine Kinase-Myocardial Band (U/L) & $12(2-137)$ & $9.8(2-76)$ & 0.34 \\
\hline Triglyceride $(\mathrm{mg} / \mathrm{dl})$ & $175(100-474)$ & $167.5(102-349)$ & 0.63 \\
\hline Total cholesterol $(\mathrm{mg} / \mathrm{dl})$ & $178.66 \pm 49.38$ & $179.96 \pm 53.85$ & 0.34 \\
\hline Low density lipoprotein $(\mathrm{mg} / \mathrm{dl})$ & $107.07 \pm 41.15$ & $115.22 \pm 49.09$ & 1.00 \\
\hline High density lipoprotein $(\mathrm{mg} / \mathrm{dl})$ & $41.68 \pm 20.64$ & $36.82 \pm 8.03$ & 0.15 \\
\hline White blood cell count $\left(10^{3} / \mathrm{mm}^{3}\right)$ & $10.93 \pm 3.14$ & $10.58 \pm 3.16$ & 0.49 \\
\hline Hemoglobin $\left(\mathrm{g} / \mathrm{dL}^{3}\right)$ & $14.27 \pm 1.86$ & $13.44 \pm 1.99$ & $\mathbf{0 . 0 0 8}$ \\
\hline Hematocrit $(\%)$ & $42.43 \pm 5.57$ & $40.21 \pm 5.85$ & $\mathbf{0 . 0 1 6}$ \\
\hline Lymphocyte $\left(10^{3} / \mathrm{mm}^{3}\right)$ & $2.4(0.4-16)$ & $2.55(1.1-13.4)$ & 0.37 \\
\hline Neutrophyle $\left(10^{3} / \mathrm{mm}^{3}\right)$ & $7.33 \pm 3.26$ & $6.96 \pm 3.11$ & 0.45 \\
\hline Platelet count $\left(10^{3} / \mathrm{mm}^{3}\right)$ & $255.12 \pm 54.00$ & $233.96 \pm 58.52$ & 0.19 \\
\hline NLR & $3(0.3-16.5)$ & $2.30(0.01-12.5)$ & $\mathbf{0 . 0 2}$ \\
\hline PLR & $108.6(14.6-511.3)$ & $91.7(17.2-225.3)$ & $\mathbf{0 . 0 1}$ \\
\hline Mean platelet volume (fL) & $7.82 \pm 1.57$ & $7.05 \pm 1.76$ & $\mathbf{0 . 0 2}$ \\
\hline Platelet distribution width $(\%)$ & $19.82 \pm 1.84$ & $19.17 \pm 1.97$ & $\mathbf{0 . 0 3}$ \\
\hline Stent diameter $\left(\mathrm{mm}^{3}\right)$ & $3.06 \pm 0.36$ & $2.92 \pm 0.30$ & $\mathbf{0 . 0 1}$ \\
\hline Stent lenght $\left(\mathrm{mm}^{3}\right)$ & $25.00 \pm 7.62$ & $20.89 \pm 7.00$ & $\mathbf{0 . 0 0 1}$ \\
\hline
\end{tabular}




\begin{tabular}{|l|l|l|l|}
\hline Syntax score & $23.26 \pm 5.38$ & $19.05 \pm 5.65$ & $\mathbf{0 . 0 0 0 0 1}$ \\
\hline Culprit lesion & & & \\
\hline Left anterior descending & $46(53)$ & $55(32)$ & 0.36 \\
\hline Left circumflex & $35(41)$ & $20(12)$ & 0.73 \\
\hline Right Coronary Artery & $18(21)$ & $24(14)$ & 0.92 \\
\hline One-vessel & $7(9)$ & $3(2)$ & 0.12 \\
\hline Two-vessel & $40(47)$ & $55(32)$ & 0.63 \\
\hline Three-vessel & $51(59)$ & $41(24)$ & 0.79 \\
\hline
\end{tabular}

NLR: Neutrophil-lymphocyte ratio; PLR: Platelet-lymphocyte ratio.

The study protocol was approved by the local ethics committee of the Adıyaman University Training and Research Hospital, and each patient provided written, informed consent.

\section{Statistical Analyze}

Data were analyzed with SPSS software version 20.0 for Windows (SPSS Inc, Chicago, Illinois). The Kolmogorov-Smirnov test was used to verify that continuous variables were normally distributed. Normally distributed variables were expressed as mean \pm standard deviation (SD), while non-normally distributed variables were expressed as median with interquartile range (IQR). The categorical variables are presented as percentages. Differences between two groups were evaluated with Student's unpaired t-test or the Mann-Whitney $U$ test for parameters with a normal or non-normal distribution. The frequencies of nominal variables were compared using Fisher's exact test and chi-square test. The Pearson test was used for correlation analysis after testing variables for normality. Statistical significance was defined as $\mathrm{P}<0.05$.

\section{Results}

The demographic and clinical data of the study population are presented in Table 1. Laboratory findings and angiographic data are in Table 2. There were 115 patients in the NR group $(63.13 \pm 10.77$ and $57 \%$ male) and 58 patients in the normal-reflow group (mean age $63.51 \pm 10.43$ and $65 \%$ male). No difference was found between the groups regarding HT, DM, Smoking, hyperlipidemia, history of $\mathrm{PCl}$, and history of $\mathrm{MI}$, whereas the Syntax Score was significantly higher in the NR group. The PLR and NLR was significantly higher in the NR group than the normal-reflow group (108.6 (14.6-511.3) vs. 91.7 (17.2-225.3), $p=0.01 ; 3$ (0.3-16.5) vs. 2.30 (0.0112.5), $\mathrm{p}=0.02$; respectively) (Table 2). Box plot graph was used to show PLR values in NR and normal-reflow groups (Figure 1). The hemoglobin was significantly higher in the NR group than the normal-reflow (14.27 $\pm 1.86)$ vs. (13.44 \pm 1.99$), p=0.008$. The Correlation between the PLR and NLR was positive and significant $(r=$ $0.68, \mathrm{p}<0.001$ ) (Figure 2).

\section{Discussion}

This study demonstrated two significant findings in patients with NSTEMI undergoing $\mathrm{pPCl}$. First, the PLR and NLR on admission were significantly higher in the post-intervention NR group. Second, there was a positive and significant correlation between the PLR and NLR in patients with NSTEMI.

NSTEMI arises from the interaction of both inflammatory and thrombotic pathways; platelets and lymphocytes play an essential role during this process. The impact of inflammation has been shown both in the initiation and in the progression of atherosclerosis, and inflammation also plays an active role during the atherosclerotic process [13]. Platelet-induced inflammatory processes might play a pivotal role in atherothrombosis [14]. The release of various mediators such as IL-1 and IL-3 during the pro-inflammatory state causes megakaryocyte proliferation and an increase in circulating platelet count [15]. Thus, increased platelet counts may indicate enhanced thrombocyte activation and a prothrombotic state [16]. Another study reported that lymphocytopenia was independently related to mechanical complications and mortality in patients with acute myocardial infarction (AMI) [17]. In response to physiologic stress during myocardial ischemia/infarction, there is a release of cortisol, and high cortisol leads to lymphopenia [18]. Lymphopenia shows a high inflammatory process [19]. Ommen, et al. have documented a decrease in the total and relative numbers of circulating lymphocytes during $\mathrm{AMI}$ and advanced congestive heart failure (HF) [20].

Moreover, a low lymphocyte count is associated with worse outcomes in NSTEMI patients [18]. Dogan, et al. showed that low lymphocyte counts are independent predictors of the NR phenomenon [21]. On the contrary, Yuksel, et al. did not find a correlation between lymphocyte and severity CAD [22]. Eventually, both thrombocytosis and lymphopenia correlate with the degree of systemic inflammation.

The increased amount of platelets can show elevated thrombocyte activation and plays an active role in the platelet-fibrin formation, and pathogenesis of ACS [23]. Stissing, et al. reported that patients with pathologically increased platelet counts have an elevated risk of thrombotic complications [24]. Recent studies have demonstrated that increased platelet count and 


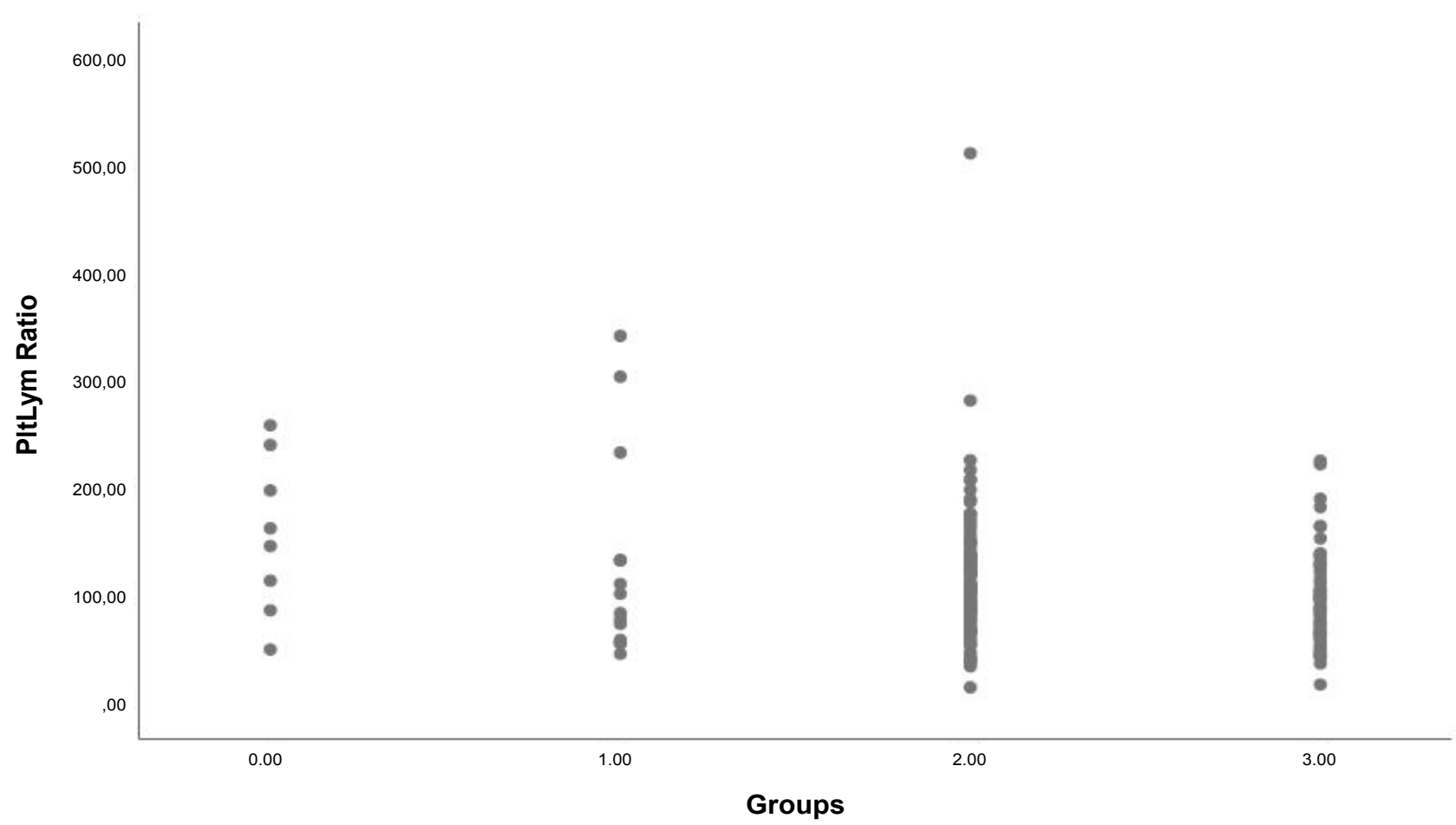

Figure 1: Box plot graph shows platelet-lymphocyte ratio (PLR) values in angiographic no-reflow $($ TIMI- $0,1,2)$ and normal-reflow (TIMI-3) groups.

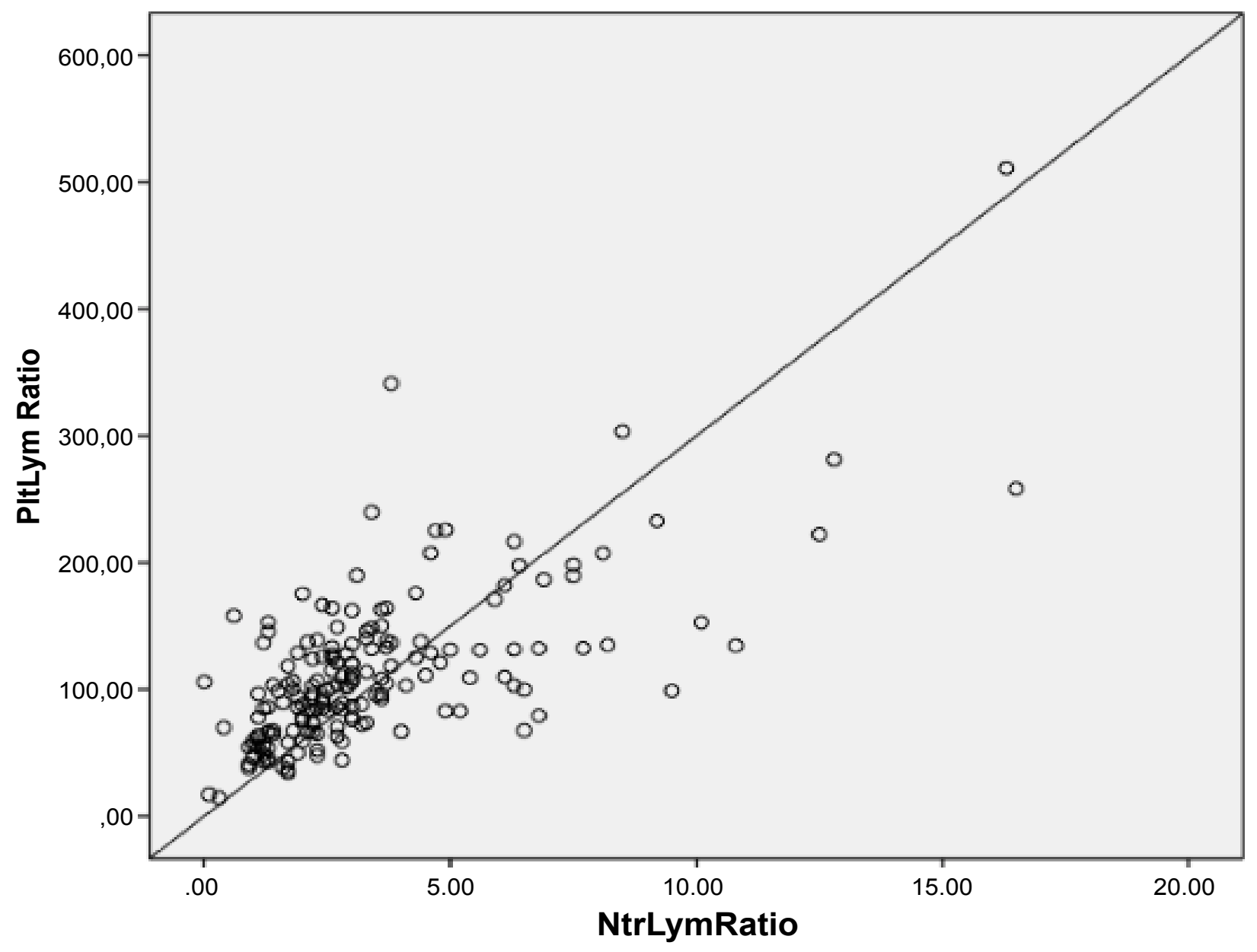

Figure 2: The Correlation between the PLR and NLR was positive and significant $(r=0.68, p<0.001)$. 
decreased lymphocyte count are associated with bad prognosis in patients with CADs $[4,25]$. Also, platelets contribute to the process of restenosis and, potentially, cardiac mortality after unstable angina/NSTEMI [26]. Muller, et al. showed that platelet counts predict the long term mortality in NSTEMI [27]. On the other hand, high PLR is a significant predictor of poor coronary collateral circulation development in patients with NSTEMI [28]. Akdag, et al. found that there was a positive correlation between PLR and the severity of CAD in patients with NSTEMI [28]. Also, PLR predicts the left ventricular systolic dysfunction in NSTEMI [29]. Moreover, PLR is a new predictor of major adverse cardiovascular outcomes [30]. The advantage of the PLR that reflects the activity of both the hemostatic and the inflammation pathways. Increased PLR is an independent predictor of long-term mortality in patients with NSTEMI [7]. Also, PLR inversely related to infarct-related artery patency [31] and associated with increased risk of in-hospital worse outcomes and six months of all-cause mortality in patients with STEMI after PCl [32]. Kurtul, et al. found that PLR was an independent predictor of the prevalence of severe coronary artery lesions, and an in-hospital predictor mortality in patients with ACS [33].

NR remains a severe complication of $\mathrm{PCl}$ of patients with AMI after revascularization [34]. NR has a strong negative impact on clinical outcome and independently associated with early post-infarct complications, late repeat hospital stays for heart failure, and mortality [35]. Also, angiographic NR after $\mathrm{PCl}$ is associated with reduced myocardial salvage, and larger infarct size [36]. NR is a multifactorial phenomenon, and five mechanisms have been recognized by Niccoli [37]: (I) pre-existing microvascular dysfunction; II) distal micro-thrombo-embolization; III) ischemic injury; IV) reperfusion injury and V) individual susceptibility. Thus, Intracoronary thrombus and high thrombus burden have an essential role in the occurrence of NR [38]. The rush of platelets and neutrophils that follows reperfusion may lead to the formation of neutrophil-platelet aggregates that plug the microcirculation and reperfusion-related injury [39]. When embolic microspheres block $>50 \%$ of coronary capillaries, Myocardial perfusion starts falling, and distal micro-thrombo-embolization during $\mathrm{PCl}$ is a predominant cause of NR [37]. PLR is not only a biomarker which reflects acute inflammatory activity but also an indicator of the thrombus burden causing embolization. In the present study, we showed that NR is related to systemic inflammation, and early detection, preventive measures, and treatment of NR may alter the outcome of $\mathrm{PCl}$ in patients with NSTEMI. Also, PLR and NLR were higher in the NR group with NSTEMI in the present study. The NLR represents the balance between neutrophil and lymphocyte levels in the body and can be an indicator of systemic inflammation [3].

\section{Conclusion}

We demonstrated that PLR was not only higher in the NR group than the normal reflow group; it also emerged as an independent predictor of NR after $\mathrm{pPCl}$ in NSTEMI patients. PLR is a simple and readily available biomarker in clinical settings. Thus, PLR can be used as a practical, inexpensive, and important tool for predicting the NR in patients with NSTEMI. PLR may also enable risk stratification and selection of a treatment strategy in patients with NSTEMI before or during coronary interventional procedures. We suggest the need for further evaluation of PLR as a predictor of NR phenomena in prospective studies.

\section{Limitations}

This present study has some limitations. This study based on a relatively small group of patients and was a single-center study. Coronary blush grade and extent of coronary thrombus parameters were not analyzed in the coronary angiography. Another study limitation was infarct size and/or ischemic damage biomarkers (myoglobin, ischemia modified albumin and cardiac fatty acid-binding protein) that we could not measure in our institution. Lack of other established inflammatory markers, such as C-reactive protein, interleukin-6, and tumor necrosis factor- $\alpha$, is another limitation of the study. The multi-center prospective and randomized studies are needed to confirm our findings.

\section{Disclosure Statement}

All authors have no declarations of interest to report.

\section{Authorship Contributions}

RA, AS performed the research and analyzed data. AS, EA, AA provided clinical data. RA, AS, EA wrote the paper, and all authors critically reviewed and edited the paper.

\section{Declarations of Interest}

None.

\section{Conflict of Interest}

None.

\section{References}

1. Chan MY, Sun JL, Newby LK, Shaw LK, Lin M, et al. (2009) Long-term mortality of patients undergoing cardiac catheterization for ST-elevation and non-ST-elevation myocardial infarction. Circulation 119: 3110-3117.

2. Jneid H (2012) The 2012 ACCF/AHA focused update of unstable angina/non-ST-elevation myocardial infarction (UA/NSTEMI) guideline: A critical appraisal. Methodist Debakey Cardiovasc J 8: 26-30.

3. Balta S, Celik T, Mikhailidis DP, Ozturk C, Demirkol S, et al. (2016) The relation between atherosclerosis and the neutrophil-lymphocyte ratio. Clin Appl Thromb Hemost 22: 405-411. 
4. Nikolsky E, Grines CL, Cox DA, Garcia E, Tcheng JE, et al. (2007) Impact of baseline platelet count in patients undergoing primary percutaneous coronary intervention in acute myocardial infarction (from the CADILLAC trial). Am J Cardiol 99: 1055-1061.

5. Ommen OSR, Gibbons GRJ, Hodge HDO, Thomson TSP (1997) The usefulness of the lymphocyte concentration as a prognostic marker in coronary artery disease. Am J Cardiol 79: 812-814.

6. Gürsoy OM, Karakoyun S, Kalçık M, Gökdeniz T, Yesin M, et al. (2014) Usefulness of novel hematologic inflammatory parameters to predict prosthetic mitral valve thrombosis. Am J Cardiol 113: 860-864.

7. Azab B, Shah N, Akerman M, McGinn JT (2012) Value of platelet/lymphocyte ratio as a predictor of all-cause mortality after non-ST-elevation myocardial infarction. J Thromb Thrombolysis 34: 326-334.

8. Smith RA, Ghaneh P, Sutton R, Raraty M, Campbell F, et al. (2008) Prognosis of resected ampullary adenocarcinoma by preoperative serum CA19-9 levels and platelet-lymphocyte ratio. J Gastrointest Surg 12: 1422-1428.

9. Ryan TJ, Bauman WB, Kennedy JW, Kereiakes DJ, King III SB, et al. (1993) Guidelines for percutaneous transluminal coronary angioplasty: A report of the american college of cardiology/american heart association task force on the assesment of diagnostic and therapeutic cardiovascular procedures (Committee on Percutaneous Transluminal Coronary Angioplasty). J Am Coll Cardiol 22: 2033-2054.

10. Oduncu V, Erkol A, Tanalp AC, Dündar C, Tanboğa I, et al. (2011) In-hospital prognostic value of admission plasma B-type natriuretic peptide levels in patients undergoing primary angioplasty for acute ST-elevation myocardial infarction. Turk Kardiyol Dern Ars 39: 540-548.

11. Amsterdam EA, Wenger NK, Brindis RG, Casey DE, Ganiats TG, et al. (2014) 2014 AHA/ACC guideline for the management of patients with non-ST-elevation acute coronary syndromes: A report of the American college of cardiology/american heart association task force on practice guidelines. J Am Coll Cardiol 64: e139-e228.

12. Lang R, Bierig M, Devereux R, Flachskampf F, Foster E, et al. (2006) Task force on chamber quantification; American college of cardiology echocardiography committee; American heart association; European association of echocardiography, European society of cardiology. Recommendations for chamber quantification. Eur $\mathrm{J}$ Echocardiogr 7: 79-108.

13. Libby P, Ridker PM, Maseri A (2002) Inflammation and atherosclerosis. Circulation 105: 1135-1143.

14. Gawaz M, Langer H, May AE (2005) Platelets in inflammation and atherogenesis. J Clin Invest 115: 3378-3384.

15. Klinger MH, Jelkmann W (2002) Role of blood platelets in infection and inflammation. J Interferon Cytokine Res 22: 913-922.

16. Gary T, Pichler M, Belaj K, Hafner F, Gerger A, et al. (2013) Platelet-to-lymphocyte ratio: A novel marker for critical limb ischemia in peripheral arterial occlusive disease patients. PLoS One 8: e67688.

17. Widmer A, Linka AZ, Jost CHA, Buergi B, Brunner-La Rocca HP, et al. (2003) Mechanical complications after myocardial infarction reliably predicted using C-reactive protein levels and lymphocytopenia. Cardiology 99: 25-31.

18. Thomson SP, McMahon LJ, Nugent CA (1980) Endogenous cortisol: A regulator of the number of lymphocytes in peripheral blood. Clin Immunol Immunopathol 17: 506-514.

19. Hotchkiss RS, Karl IE (2003) The pathophysiology and treatment of sepsis. N Engl J Med 348: 138-150.

20. Ommen SR, Hodge DO, Rodeheffer RJ, McGregor CG, Thomson SP, et al. (1998) Predictive power of the relative lymphocyte concentration in patients with advanced heart failure. Circulation 97: 19-22.

21. Dogan NB, Ozpelit E, Akdeniz S, Bilgin M, Baris N (2015) Simple clinical risk score for no-reflow prediction in patients undergoing primary Percutaneous Coronary Intervention with acute STEMI. Pak J Med Sci 31: 576-581.

22. Yüksel M, Yıldız A, Oylumlu M, Akyüz A, Aydın M, et al. (2016) The association between platelet/lymphocyte ratio and coronary artery disease severity. Anatol J Cardiol 15: 640-647.

23. Celik T, Balta S, Mikhailidis DP, Ozturk C, Aydin I, et al. (2017) The relation between no-reflow phenomenon and complete blood count parameters. Angiology 68: 381-388.

24. Stissing T, Dridi NP, Ostrowski SR, Bochsen L, Johansson PI (2011) The influence of low platelet count on whole blood aggregometry assessed by Multiplate. Clin Appl Thromb 17: e211-e217.

25. Yılmaz S, Sen F, Ünal S, Yayla C, Özeke Ö, et al. (2015) Usefulness of the platelet-to-lymphocyte ratio in predicting bare-metal stent restenosis. Scand Cardiovasc J 49: 39-44.

26. Johansen O, Brekke M, Seljeflot I, Semb A, Arnesen H (2004) Blood platelet count and reactivity are associated with restenosis 6 months after coronary angioplasty. Scand Cardiovasc J 38: 211-215.

27. Mueller C, Neumann F-J, Hochholzer W, Trenk D, Zeller T, et al. (2006) The impact of platelet count on mortality in unstable angina/non-ST-segment elevation myocardial infarction. Am Heart J 151: e1214-e1227.

28. Akdag S, Akyol A, Asker M, Ozturk F, Gumrukcuoglu HA (2016) The relation of Platelet-lymphocyte ratio and coronary collateral circulation in patients with non-ST segment elevation myocardial infarction. Postepy Kardiol Interwencyjnej 12: 224-230.

29. Bekler A, Gazi E, Yılmaz M, Temiz A, Altun B, et al. (2015) Could elevated platelet-lymphocyte ratio predict left ventricular systolic dysfunction in patients with non-ST elevated acute coronary syndrome? Anatol J Cardiol 15: 385-390.

30. Balta S, Ozturk C (2015) The platelet-lymphocyte ratio: A simple, inexpensive and rapid prognostic marker for cardiovascular events. Platelets 26: 680-681.

31. Yayla Ç, Akboğa MK, Canpolat U, Akyel A, Yayla KG, et al. (2015) Platelet to lymphocyte ratio can be a predictor of infarct-related artery patency in patients with ST-segment elevation myocardial infarction. Angiology 66: 831-836.

32. Akkaya E, Gul M, Ugur M (2014) Platelet to lymphocyte ratio: A simple and valuable prognostic marker for acute coronary syndrome. Int J Cardiol 177: 597-598.

33. Kurtul A, Murat SN, Yarlioglues M, Duran M, Ergun G, et al. (2014) Association of platelet-to-lymphocyte ratio with severity and complexity of coronary artery disease in patients with acute coronary syndromes. Am J Cardiol 114: 972-978.

34. Abbo KM, Dooris M, Glazier S, O'Neill WW, Byrd D, et al. (1995) Features and outcome of no-reflow after percutaneous coronary intervention. Am J Cardiol 75: 778-782. 
35. Brosh D, Assali AR, Mager A, Porter A, Hasdai D, et al. (2007) Effect of no-reflow during primary percutaneous coronary intervention for acute myocardial infarction on sixmonth mortality. Am J Cardiol 99: 442-445.

36. Ndrepepa G, Tiroch K, Fusaro M, Keta D, Seyfarth M, et al. (2010) 5-year prognostic value of no-reflow phenomenon after percutaneous coronary intervention in patients with acute myocardial infarction. J Am Coll Cardiol 55: 23832389.

37. Niccoli G, Scalone G, Lerman A, Crea F (2015) Coronary microvascular obstruction in acute myocardial infarction. Eur Heart J 37: 1024-1033.

38. Tanboga IH, Topcu S, Aksakal E, Kalkan K, Sevimli S, et al. (2014) Determinants of angiographic thrombus burden in patients with ST-segment elevation myocardial infarction. Clin Appl Thromb 20: 716-722.

39. Mehta JL, Nichols WW, Mehta P (1988) Neutrophils as potential participants in acute myocardial ischemia: relevance to reperfusion. J Am Coll Cardiol 11: 1309-1316. 